\title{
The Mediating Effect of Organizational Support between Job Insecurity and Turnover Intention in Private Hospitals
}

\author{
Mustafa Günalan ${ }^{1} \&$ Adnan Ceylan ${ }^{2}$ \\ ${ }^{1}$ Havran Vocational School, Balıkesir University, Balıkesir, Turkey \\ ${ }^{2}$ Department of Business Administration, Gebze Technical University, Kocaeli, Turkey \\ Correspondence: Mustafa Günalan, Havran Vocational School, Ebubekir Mah. Cumhuriyet Cad. Havran, \\ Balıkesir,10560, Turkey. E-mail: gunalan@balikesir.edu.tr
}

Received: May 11, 2015

Accepted: June 5, 2015

Online Published: September 18, 2015

doi:10.5539/ijbm.v10n10p74

URL: http://dx.doi.org/10.5539/ijbm.v10n10p74

\begin{abstract}
The main purpose of this study is to investigate the mediator role of health workers' organizational support perceptions between job insecurity dimensions and turnover intentions. Participants of the study were 217 nurses and allied health professionals working in four private hospitals located in Balikesir, Turkey. According to results of hierarchical regression analyses, both quantitative and qualitative dimensions of job insecurity had positive effects on turnover intention. Furthermore, perceived organizational support had a partial mediator role between qualitative job insecurity and turnover intention. On the contrary, the results did not reveal any mediator effect of perceived organizational support between quantitative job insecurity and turnover intention since quantitative job insecurity did not have a significant effect on perceived organizational support. In the light of these results, several managerial suggestions related to support perceptions, quantitative and qualitative job insecurity concerns, and turnover intentions of health workers were provided, and implications for future researches were discussed.
\end{abstract}

Keywords: quantitative job insecurity, qualitative job insecurity, perceived organizational support, turnover intention

\section{Introduction}

In recent years, number of private hospitals in Turkey has rapidly increased due to the changes in Turkish health policy in accordance with European Union membership processes. While there were 774 public hospitals and 271 private hospitals in 2002, there were 832 public hospitals and 541 private hospitals in 2012 (Bora Başara et al., 2012, p. 65). Depending on the profit orientation of private hospitals, this increment may cause several changes in health workers' working and labor market conditions. It is important to note that health workers are, at the same time, employees in the private sector, and bounded to an employer with a contract. This condition may bring some organizational and individual issues into health sector such as job insecurity and turnover.

Although there is not any study determining the turnover rates in Turkish health care sector, it is known that the sector has high turnover rates in the world (L. J. Hayes et al., 2006; Park, Lee, \& Cho, 2012). ), and high turnover rates may cause negative outcomes for both health workers and private hospitals. These outcomes could be ranged as poor individual and organizational performance (Wagner, 2010; Daouk-Öyry, Anouze, Otaki, Dumit, \& Osman, 2014), decrease in quality of care and fulfilling patient needs (Shields \& Ward, 2001; Wagner, 2010), and despondency (Cavanagh \& Coffin, 1992; Wagner, 2010). At the individual level, turnover behavior is unpreventable since it is currently actualized (Harris, Harris, \& Harvey, 2008). Therefore, preventing turnover requires managing predictors of turnover (Takase, 2010). It is commonly recognized that intention to leave is the strongest antecedent of turnover behavior (Youngblood, Mobley, \& Meglino, 1983; Tett \& Meyer, 1993; Podsakoff, LePine, \& LePine, 2007), and an important step of employee turnover behavior process (Youngblood et al., 1983). Concerning this importance, service sector employees' turnover intention also attracted researchers' attention (e.g. Takase, 2010; AlBattat \& Som, 2013).

There are great amount of studies in the literature that examined numerous precursors of turnover intention (e.g. Tett \& Meyer, 1993; Podsakoff et al., 2007) including job insecurity (e.g. Staufenbiel \& König, 2010; Emberland $\&$ Rundmo, 2010). The concept of job insecurity attracted researchers' attention depending on economic crises 
and organizational changes such as downsizing, restructuring and merging in the last quarter of 20th century (Ashford, Lee, \& Bobko, 1989). Greenhalgh and Rosenblatt (1984) defined job insecurity as a perception of impotency to retain a job that is under threat. This definition addresses to an insecurity perception on totally losing a job, and is widely accepted in the literature (Sverke, Hellgren, \& Näswall, 2002; Cheng \& Chan, 2007).

While the definition of job insecurity implies a concern regarded to a total job loss, Greenhalgh and Rosenblatt (1984), in their conceptual study, also remarked 'losing valued job features' as a neglected side of job insecurity. From this point of view, Hellgren, Sverke, and Isaksson (1999) conceptualized insecurity perception of losing total job as quantitative job insecurity and losing valued features of a job as qualitative job insecurity, and proposed that relationships of these dimensions with outcome variables may differ. Thus, quantitative job insecurity implies a concern about losing a job itself, and qualitative job insecurity indicates losing valued job features such as retrogression of working conditions, downgrading, and decrease in salary (Swerke \& Hellgren, 2002). In terms of especially private hospitals, since they are also profit-oriented organizations, motives of both quantitative and qualitative dimensions of job insecurity such as downsizing, restructuring, decrease in salary, and changed work conditions are possible issues that private hospital managements and employees may be confronted (Laine, Van der Heijden, Wickström, Haaselhorn, \& Tackenberg, 2009).

In the literature, another important precursor of turnover intention is perceived organizational support which is evaluated as reciprocal of organizational commitment of employees in terms of social exchange, and summarized as the commitment of organizations to employees. Thus, it is identified as employees' beliefs related to how the organization values their contribution and cares about their well-being (Eisenberger, Huntington, Hutchison, \& Sowa, 1986). Researchers broadly argued the possible negative effect of perceived organizational support on turnover intention, and purposed that if employees' perceptions about their organizations support are positive, then, as reciprocal behavior, employees will tend not to leave the employer organization and their turnover intention will decrease (e.g. Perryer, Jordan, Firns, \& Travaglione, 2010; Newman, Thanacoody, \& Hui, 2012).

With reference to these points of views, the research questions of this study are: (1) how nurses' and other allied health professionals' quantitative and qualitative job insecurity perceptions affect turnover intention, (2) how these health workers' organizational support perceptions affect their turnover intentions, and (3) do these health workers' organizational support perceptions have any mediator roles on the effects of job insecurity dimensions on turnover intentions? Therefore, the main objectives of the study are to inspect the effects of quantitative and qualitative job insecurities and organizational support perceptions on turnover intention and to mediator effect of perceived organizational support between job insecurity dimensions-turnover intention associations.

We believe that this study will contribute the literature in several ways. First, while most of previous studies investigated only the quantitative dimension of job insecurity, the current study held two dimensions as quantitative and qualitative job insecurities. Thus, the study will contribute to better understanding health workers' job insecurities. Second, the mediator role of perceived organizational support, which is not call attention of researchers especially in health care field, will be investigated in the study. Thereby, the effect of health workers' positive organizational support perceptions on turnover intentions, and its mediator role, also, will be better understood. Furthermore, we believe that private hospital managers may benefit from the findings of this study in their practices and managerial policy developments in order to provide lower turnover rates, and retain employees in their organizations.

The study is organized as follows. In the second section, we review the literature about predicted relationships between variables, especially focusing on the health care sector and propose research hypotheses. The third section describes the methods used in the study. In this part of the study, brief information about measurement of the variables, and multiple regression analyses used in the study is included. In the fourth section, empirical results of the analyses related to effects of job insecurity dimensions, and perceived organizational support on turnover intention, and mediator role of perceived organizational support are indicated. Finally, discussions and implications for private health sector managers and researchers are provided in the last section.

\section{Literature Review and Research Hypotheses}

\subsection{Job Insecurity Dimensions and Turnover Intention}

In their conceptual study, Greenhalgh and Rosenblatt (1984) suggested that the more employees feel insecure about retaining their job, the more they may think on or actively search to find another employer organization. Based on this assumption, job insecurity-turnover intention relationship has long received attention of researchers. Results of the studies that inspected the effect of job insecurity on turnover intention showed that there is a positive association between these variables (e.g. Sora, Caballer, \& Peiró, 2010). In terms of healthcare 
profession, studies that examined the relationship between these two variables also found a positive association between these two variables (e.g. Mosadeghard, 2013; Zeytinoglu, Denton, \& Plenderleith, 2011; Laine et al., 2009). It should be noted that these studies focused on quantitative dimension of job insecurity only. In accordance with Greenhalgh and Rosenblatt (1984)'s suggestion, and the results of previous studies, we proposed the following assumption:

Hypothesis 1a: Quantitative job insecurity has a positive effect on turnover intention.

Researches that investigated the effects of both quantitative and qualitative dimensions of job insecurity on turnover intention are rare. While, in their longitudinal research, Hellgren et al. (1999) did not find a significant effect of quantitative job insecurity on turnover intention, while the results of their research demonstrated a significant effect of qualitative job insecurity on turnover intention. Laine et al. (2009), in their cross-cultural study among eleven European countries, investigated effect of nurses' job insecurity concerns on turnover intention. Depending on the countries' health sector and labour market conditions, the results of the research showed that while there were significant positive effects of quantitative job insecurity on turnover intention in four countries, there were not any significant effects in seven countries. In addition, the results of their study demonstrated that while there were significant positive effects of qualitative job insecurity on turnover intention in nine countries, there were not any significant effects in two countries. According to results of these researches, we may assume that the more workers get anxious about losing valued job features, the more they intent to leave the employer organization. Thus, we proposed the following hypothesis:

Hypothesis 1b: Qualitative job insecurity has a positive effect on turnover intention.

\subsection{Perceived Organizational Support and Turnover Intention}

In the literature, results of the studies showed the negative effect of perceived organizational support on turnover intention (e.g. Perryer et al., 2010; Newman et al., 2012). In health care literature, studies also presented similar results. For example, Kim et al. (2013), in their study on Korean nurses, found that nurses with higher organizational support perception showed lower intention to leave. Therefore, it could be asserted that in health workers' decisions about staying in or leaving the hospital, the importance of the perceptions of these health workers about employer hospitals' support to their well-being would increase. Thus, we assumed the following hypothesis:

Hypothesis 2: Perceived organizational support has a negative effect on turnover intention.

\subsection{The Mediating Effect of Perceived Organizational Support}

The mediator role of perceived organizational support between various variables attracted researchers' attention in the organization literature (e.g. Hochwarter, Kacmar, Perrewé, \& Johnson, 2003; Ohana, 2012). However, studies investigating the mediating effect of organizational support between job insecurity and turnover intention are rare. For example, Zeytinoglu et al. (2011) inspected the mediator role of organizational support on job insecurity-turnover intention relationship in their research on nurses, and found a mediator effect of perceived organizational support between these variables. It should be considered that authors used the quantitative dimension of job insecurity in their research. However, we also examined the qualitative job insecurity. Therefore, based on this result, we asserted following hypotheses:

Hypothesis 3a: Perceived organizational support has a mediator effect between quantitative job insecurity and turnover intention.

Hypothesis 3b: Perceived organizational support has a mediator effect between qualitative job insecurity and turnover intention.

\section{Method}

\subsection{Sample and Procedure}

The sample of the current study, which was determined with convenience sampling, consists of nurses and other allied health professionals (e.g. emergency medical technician, operating room technician, medical technician) working at four private hospitals in Balikesir, Turkey. We implemented face-to-face survey containing self-reported questionnaires to measure health professionals' perceptions of organizational support, quantitative and qualitative job insecurities and turnover intention.

Before data collection, we contacted with public relations managers of these hospitals. After obtaining approval to implement the questionnaire, we discussed the procedure of the research with them. Then, we delivered a total 340 questionnaires to public relations managers of these hospitals and public relations department workers distributed questionnaires in envelopes to participants. In the process of data collection, aim of the study, secrecy 
of answers and voluntariness of participation was clarified with a cover letter attached to the questionnaire. In order to ensure the participants on secrecy and voluntariness, the questionnaires also were not collected by public relations workers of hospitals, and we utilized sealed envelopes and boxes that located in staff rooms. A total 248 questionnaires of 340 were returned, some of them were eliminated in data screening process and 217 of them are used in the analysis. Thus, we yielded a 63 percent response rate.

\subsection{Measurement of Variables}

A self-administrated questionnaire with items about dimensions of job insecurity, perceived organizational support and turnover intention was used in the research. Because participants of the study were Turkish, we used back-translation process (Ronen \& Shenkar, 1985) in the preparation of questionnaire. The scales were translated to Turkish by researchers who are proficient in English. As a check, an independent linguist, also, back translated Turkish version of the questionnaire to English. We used 5-points Likert type scaling that ranges from 1 (strongly disagree) to 5 (strongly agree).

Perceived job insecurity was measured using a 6-items scale. Three items measuring quantitative job insecurity were adapted from Hellgren et al. (1999)'s study, and the other three items measuring qualitative job insecurity were adapted from Størseth (2006)'s study. Participants were requested to indicate their agreement level with statements about their job insecurity perceptions. Example item for quantitative jo insecurity is "I feel uneasy about losing my job in this hospital in the near future" and qualitative job insecurity is "there are rumors concerning changes at hospital."

Perceived organizational support was measured with shortened version of Survey of Perceived Organizational Support (SPOS) (Eisenberger et al., 1986). Hochwarter et al. (2003) determined 8 items according to highest factor loadings of SPOS items. Participants were requested to indicate their agreement level with statements about their organizational support perceptions about their hospitals. An example item of the scale for perceived organizational support is "My hospital really cares about my well-being."

Turnover intention was measured using a scale with three items. The scale was adapted from the scale developed by Walsh, Ashford and Hill (1985, as cited in Ducharme, Knudsen, \& Roman, 2008). We requested participants to remark their agreement degree with statements about their intentions to leave their organizations. An example item of scale for turnover intention is "I am actively looking for a job at another hospital."

\subsection{Data Analysis}

In data analysis process, we used descriptive statistics to identify characteristics of participants. We also implemented an independent samples $t$-test to determine whether nurses and other allied health professionals represented same sample. Then, we performed an exploratory factor analysis (EFA) by using principal axis factor extraction with promax rotation method to identify sub-factors of the scale, and ensure convergent and discriminant validity. We used Cronbach's Alpha reliability coefficients to estimate internal consistencies of scales. In order to assess both proposed hypotheses and mediator effects, we implemented two separate multiple regression analyses. In multiple regression analyses, we followed Baron and Kenny (1986) steps to assess mediating effect. According to Baron and Kenny, in mediation analysis, there should be significant relations between the independent variable and the mediator (a path), the mediator and the dependent variable (b path), and the independent variable and the dependent variable (c path). In addition, when the relation between independent and dependent variables controlled through the mediator, previous significant relation between independent and dependent variables should not be significant or be decreased (c' path). In order to test these relationships, we used multiple regression analysis. We also used bootstrap resampling method and Sobel test to assess validity of the indirect effects of perceived organizational support in two mediation models (A. F. Hayes, 2013).

\section{Results}

\subsection{Sample Characteristics}

The demographic characteristics of the participants were presented in Table 1. In the descriptive statistics analysis of the participants, $57.6 \%$ were nurses, and $42.4 \%$ were other allied health professionals. In the results, $89.6 \%$ of nurses were female while $46.7 \%$ of other allied health professionals were female. Distribution of age groups showed similar percentages in general, nurses, and other allied health professionals. 47.9 percent of participants' were 25 years old or less in general (nurses $44.8 \%$ and other allied health professionals $52.2 \%$ ). Education level of 49.3 percent of the respondents was high school. In addition, the mean of respondents' working hours is 52.6 hours per week.

In order to determine whether nurses and other allied health professionals represent the same sample, we also 
conducted an independent samples t-test. The quantitative job insecurity perceptions did not significantly differ between nurses and other allied health professionals $(M=2.67,2.60 ; t=.493, p=.622)$. In addition, qualitative job insecurity perception $(M=2.58,2.47 ; t=.917, p=.360)$, perceived organizational support $(M=3.37,3.48 ; t$ $=-1.049, p=.296)$ and turnover intention $(M=2.51,2.43 ; t=.631, p=.529)$ did not show any differences between nurses and other allied health professionals. Therefore, using nurses and other allied health professionals as a unique sample was appropriate.

Table 1. Demographic characteristics of the participants

\begin{tabular}{llll}
\hline Characteristics & $\begin{array}{l}\text { General }(\mathbf{N}=\mathbf{2 1 7}) \\
\mathbf{N}(\mathbf{\%})\end{array}$ & $\begin{array}{l}\text { Nurses }(\mathbf{N}=\mathbf{1 2 5}) \\
\mathbf{N}(\mathbf{\%})\end{array}$ & $\begin{array}{l}\text { AHPs }(\mathbf{N}=\mathbf{9 2}) \\
\mathbf{N}(\mathbf{\%})\end{array}$ \\
\hline $\begin{array}{l}\text { Age group (yr) } \\
\leq 25\end{array}$ & $104(47.9)$ & $56(44.8)$ & $48(52.2)$ \\
$26-35$ & $79(36.4)$ & $45(36)$ & $34(37)$ \\
$36-45$ & $18(8.3)$ & $11(8.8)$ & $7(7.6)$ \\
$\geq 46$ & $16(7.4)$ & $13(10.4)$ & $3(3.3)$ \\
Range & $18-56$ & $18-56$ & $18-52$ \\
$M(S D)$ & $28.3(8.9)$ & $29.4(9.6)$ & $26.9(7.6)$ \\
Gender & & & $43(46.7)$ \\
Female & $155(71.4)$ & $112(89.6)$ & $49(53.3)$ \\
Male & $62(28.6)$ & $13(10.4)$ & $42(45.7)$ \\
Marital Status & & & $50(54.3)$ \\
Married & $105(48.4)$ & $63(50.4)$ & $50(54.3)$ \\
Not Married & $112(51.6)$ & $62(49.6)$ & $30(32.6)$ \\
Education & & & $11(12.0)$ \\
High School & $107(49.3)$ & $57(45.6)$ & $1(1.1)$ \\
College & $58(26.7)$ & $28(22.4)$ & $35-66$ \\
University & $50(23.1)$ & $39(31.29$ & $53.7(7.51)$ \\
Graduate School & $2(.9)$ & $1(.8)$ &
\end{tabular}

\subsection{Validities and Reliabilities}

Initially, we examined the factorability of 17 items of the scale. The Kaiser-Meyer-Olkin (KMO) measure of sampling adequacy was .79 , and Bartlett's test of sphericity was significant $\left(\chi^{2}=1395,02, \mathrm{df}=120, p=.001\right)$. These results indicated that performing an EFA is appropriate with the data. Then, we performed principal axis factor extraction and promax rotation method in EFA because items of the scale did not demonstrate normal distribution (Gaskin \& Happell, 2014). In the first analysis, one item of perceived organizational support scale was eliminated since it deranged the distribution of items to factor structures. With the remaining 16 items, we conducted EFA again and four factors were extracted. The factor loadings of items ranged from .52 to .80 for perceived organizational support ( 7 items), .44 to .86 for turnover intention ( 3 items), .47 to .83 for quantitative job insecurity ( 3 items), and .56 to .73 for qualitative job insecurity ( 3 items). With these EFA results, convergent and discriminant validities were met (Hair, Black, Babin, \& Anderson, 2010, p. 126). Factor loadings, explained variance percentiles, and inter-item correlations of each factor were presented in Table 2.

In the research, we also performed an internal consistency reliability analysis through Cronbach's Alpha $(\alpha)$. According to results, $\alpha$ reliabilities of subscales of perceived organizational support was $.86(M=3.41, S D$ $=.76)$, quantitative job insecurity was $.74(M=2.64, S D=.92)$, qualitative job insecurity was $.73(M=2.53, S D$ $=.91)$, and turnover intention was $.73(M=2.48, S D=.90)$. These results reflected that reliabilities of all scales used in the questionnaire were adequate. When we inspected the correlation coefficients, the results presented strong relationships between variables except between quantitative job insecurity and perceived organizational support $(r=-.08, p=.23$ ). Means, standard deviations, $\alpha$ values, and correlations between factors were presented in Table 3. 
Table 2. Factor loadings of items ${ }^{\mathrm{a}}$, explained variance percentages of factors, and inter-item correlations of factors

\begin{tabular}{|c|c|c|c|}
\hline Items & Loadings & $\%$ of Variance & $r^{b}$ \\
\hline Organizational Support & & 26.73 & \\
\hline POS1 & .80 & & \\
\hline POS2 & .79 & & \\
\hline POS5 & .76 & & \\
\hline POS7 & .68 & & $.35-.70$ \\
\hline POS8 & .66 & & \\
\hline POS3 & .63 & & \\
\hline POS6 & .52 & & \\
\hline Turnover Intention & & 13.74 & \\
\hline TI3 & .86 & & \\
\hline TI2 & .74 & & $.39-.66$ \\
\hline TI1 & .44 & & \\
\hline Quantitative Job Insecurity & & 6.87 & \\
\hline QNT-JIS1 & .83 & & \\
\hline QNT-JIS3 & .77 & & $.40-.59$ \\
\hline QNT-JIS2 & .47 & & \\
\hline Qualitative Job Insecurity & & 5.36 & \\
\hline OLT-JIS6 & .73 & & \\
\hline QLT-JIS5 & .59 & & $.44-.49$ \\
\hline QLT-JIS4 & .56 & & \\
\hline Total & & 52.70 & \\
\hline
\end{tabular}

Table 3. Means, standard deviations, correlations and reliabilities

\begin{tabular}{llllllll}
\hline Variables & $\mathbf{M}$ & SD & $\boldsymbol{\alpha}$ & $\mathbf{1}$ & $\mathbf{2}$ & $\mathbf{3}$ & $\mathbf{4}$ \\
\hline Quantitative Job İnsecurity & 2.64 & .92 & .74 & - & & & \\
Qualitative Job Insecurity & 2.53 & .91 & .72 & $.34^{* *}$ & - & & \\
Perceived Organizational Support & 3.41 & .76 & .86 & -.08 & $-.13^{*}$ & - & \\
Turnover Intention & 2.48 & .90 & .73 & $.22^{* *}$ & $.31^{* *}$ & $-.42^{* *}$ \\
\hline
\end{tabular}

Note. $\alpha=$ Cronbach's Alpha, $M=$ Mean, $S D=$ Standart deviations;

${ }^{*} p<.05, \quad{ }^{* *} p<.01$.

\subsection{Hypotheses Testing}

Prior to multiple regression analyses, we controlled whether there was any multicollinearity issue between variables via collinearity statistics. In the collinearity analysis, tolerance values ranged from .87 to .98 , and variance inflation factor values ranged from 1.02 to 1.14 . These results showed that there was not any multicollinearity issue for implementing regression analyses (Hair et al., 2010, p. 204). In order to analyze the mediator effect of perceived organizational support on the relationships between quantitative and qualitative job insecurity dimensions and turnover intention, we performed separate multiple regression analyses, which also test the other hypotheses beside mediation hypotheses proposed in this study. 


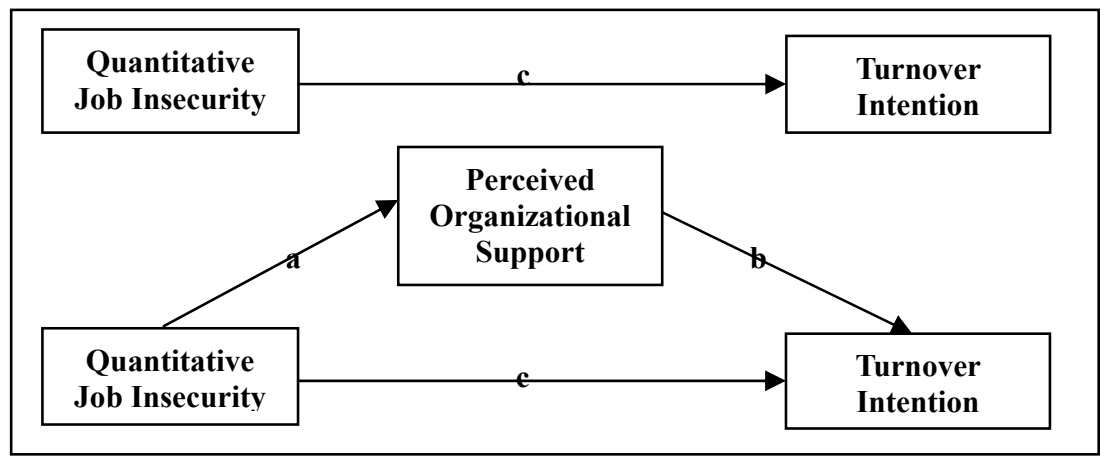

Figure 1. The first mediation model of the mediator role of perceived organizational support between quantitative job insecurity and turnover intention

In the analysis of the first mediation model, we inspected the mediator effect of perceived organizational support on the relationship between quantitative job insecurity and turnover intention as demonstrated in Figure 1. The results of the first regression analysis revealed that quantitative job insecurity was positively related to turnover intention $(\beta=.222, p=.001)$. Thus the result supported $H 1_{a}$ (c-path). This result indicated that the more health workers perceive higher level of quantitative job insecurity the more they intent to leave their hospitals. The results also showed that perceived organizational support, the mediator, was negatively associated with turnover intention $(\beta=-.409, p=.001)$, which was supportive for $H 2$ (b-path). This result implied that turnover intentions of health workers with higher level of organizational support perception get decrease. Although the results of the first regression analysis met the second and the third conditions of Baron-Kenny steps, the third condition, a-path, was not met. The showed that there was not any significant effect of quantitative job insecurity on perceived organizational support $(\beta=-.081, p>.05)$. This result indicated that analyzing the mediator effect of perceived organizational support between quantitative job insecurity and turnover intention was not appropriate, thus, there was not a mediation effect of perceived organizational support between quantitative job insecurity and turnover intention. The findings of the mediation analysis also support that result. The results demonstrated that when perceived organizational support included the regression with quantitative job insecurity, the effect of quantitative job insecurity on turnover intention decreased $(\beta=.189)$ but it was still significant $(p<.05)$. Level of the decrease in this effect which is called indirect effect was $\beta=.033$ but it was not between bootstrap confidence interval $(\mathrm{LLCI}=-.035$, ULCI $=.108)$. Therefore, $H 3_{a}$ was not supported. Thus, we could say that there was not any mediator effect of perceived organizational support between quantitative job insecurity and turnover intention. The results of the first regression analysis demonstrated in Table 4.

Table 4. The mediator role of perceived organizational support between quantitative job insecurity and turnover intention

\begin{tabular}{|c|c|c|c|c|c|}
\hline & $\beta$ & $\mathbf{p}$ & $\mathbf{t}$ & LLCI $^{a}$ & ULCI $^{a}$ \\
\hline \multicolumn{6}{|l|}{ Model 1} \\
\hline $\begin{array}{l}\text { QNT-JIS } \rightarrow \text { POS (a path) } \\
\mathrm{R}^{2}=.007 \\
\mathrm{~F}=1.431\end{array}$ & -.081 & .233 & -1.196 & -.215 & .053 \\
\hline \multicolumn{6}{|l|}{ Model 2} \\
\hline $\begin{array}{l}\text { QNT-JIS } \rightarrow \text { TI (c path) } \\
\mathrm{R} 2=.050 \\
\mathrm{~F}=11.187\end{array}$ & .222 & .001 & 3.345 & .091 & .354 \\
\hline \multicolumn{6}{|l|}{ Model 3} \\
\hline $\begin{array}{l}\text { POS } \rightarrow \text { TI (b path) } \\
\text { QNT-JIS } \rightarrow \text { TI (c'path) } \\
\text { R2 }=.216 \\
\text { F=29.414 }\end{array}$ & $\begin{array}{l}-.409 \\
.189\end{array}$ & $\begin{array}{l}.001 \\
.002\end{array}$ & $\begin{array}{l}-6.733 \\
3.114\end{array}$ & $\begin{array}{l}-.529 \\
.069\end{array}$ & $\begin{array}{l}-.289 \\
.309\end{array}$ \\
\hline Indirect Effect & .033 & & & -.035 & .108 \\
\hline
\end{tabular}

LLCI $=$ Lower level of confidence interval, ULCI=Upper level of confidence interval

${ }^{\mathrm{a}}$ Bias corrected confidence intervals. 


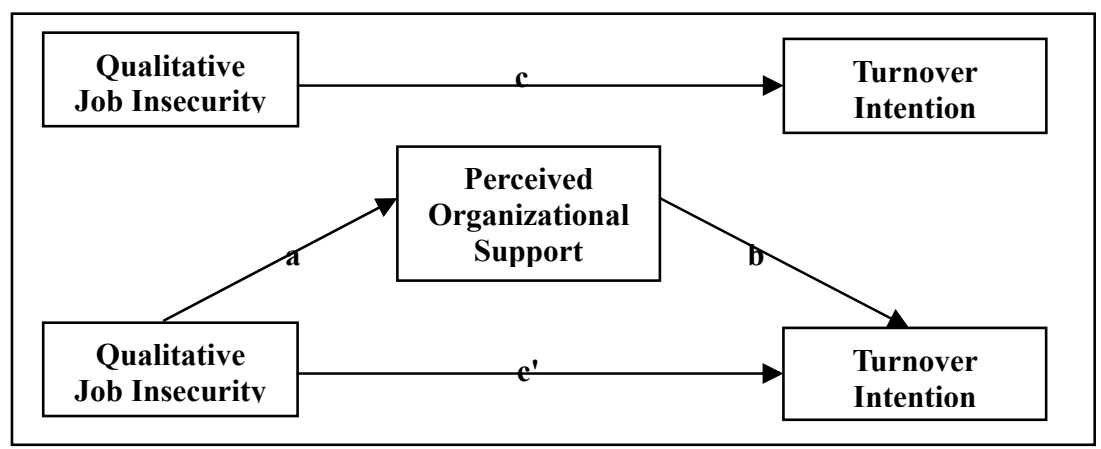

Figure 2. The second mediation model of the mediator role of perceived organizational support between qualitative job insecurity and turnover intention

In the analysis of the second model, the results revealed that qualitative job insecurity was negatively associated with perceived organizational support $(\beta=-.134, p<.05)$. Thus, the first condition of Baron-Kenny steps, a-path, was met. The results also showed that perceived organizational support was negatively related to turnover intention $(\beta=-.389, p=.001)$. This result indicated that the second condition of the Baron-Kenny steps, which was demonstrated with b-path, was met, and supported the $\mathrm{H}_{2}$, again. The third condition of Baron-Kenny steps, the c-path, and $H 1 b$ also supported. According to results, qualitative job insecurity had a positive effect on turnover intention $(\beta=.314, p=.001)$. This result indicated that when health workers perceive job insecurity with high level not about losing a job itself but about losing important job features, their intention to leave the current organization would increase. These results, also, implied that the mediation analysis was appropriate. When we included perceived organizational support to the regression with qualitative job insecurity in order to test the indirect effect of qualitative job insecurity on turnover intention through perceived organizational support, the effect of qualitative job insecurity on turnover intention decreased to level of $\beta=.262$ with $p=.001$ significance level. This significance of the effect implied that there was not a full mediation. In order to determine whether the indirect effect was statistically significant and, thus, there was any partial mediation, we used bootstrap resampling method. In the analysis, $95 \%$ confidence interval of the indirect effect was obtained with 5000 bootstrap resamples (A. F. Hayes, 2013). The results showed the indirect effect size of perceived organizational support on the relationship between qualitative job insecurity and turnover intention as $\beta=.052$ and it was in the confidence interval (LLCI $=-.035$, ULCI $=.108$ ). Thus, the $H 3_{b}$ was supported. The result indicated that when health workers perceive positive organizational support, this positive perception would absorb the effect of qualitative job insecurity on turnover intention. The multiple regression analysis results for the second model presented in Table 5.

Table 5. The mediator role of perceived organizational support between quantitative job insecurity and turnover intention

\begin{tabular}{|c|c|c|c|c|c|}
\hline & $\boldsymbol{\beta}$ & $\mathbf{p}$ & $\mathbf{t}$ & LLCI $^{a}$ & ULCI $^{\mathrm{a}}$ \\
\hline \multicolumn{6}{|l|}{ Model 1} \\
\hline $\begin{array}{l}\text { QLT-JIS } \rightarrow \text { POS (a path) } \\
\text { R2 }=.018 \\
\mathrm{~F}=3.947\end{array}$ & -.134 & .048 & -1.987 & -.268 & -.001 \\
\hline \multicolumn{6}{|l|}{ Model 2} \\
\hline $\begin{array}{l}\text { QLT-JIS } \rightarrow \text { TI (c path) } \\
\mathrm{R} 2=.099 \\
\mathrm{~F}=23.571\end{array}$ & .314 & .001 & 4.855 & .187 & .442 \\
\hline \multicolumn{6}{|l|}{ Model 3} \\
\hline $\begin{array}{l}\text { POS } \rightarrow \text { TI (b path) } \\
\text { QLT-JIS } \rightarrow \text { TI (c' path) } \\
\text { R2 }=.248 \\
\text { F= 35.197 }\end{array}$ & $\begin{array}{l}-.389 \\
.262\end{array}$ & $\begin{array}{l}.001 \\
.001\end{array}$ & $\begin{array}{l}-6.504 \\
4.380\end{array}$ & $\begin{array}{l}-.507 \\
.144\end{array}$ & $\begin{array}{l}-.271 \\
.380\end{array}$ \\
\hline Indirect Effect & .052 & & & .001 & .127 \\
\hline
\end{tabular}

${ }^{\text {a }}$ Bias corrected confidence intervals. 


\section{Discussion}

The current study purposed to determine health workers' responses to quantitative and qualitative job insecurities in terms of turnover intentions, and whether perceived organizational support mediated these responses. The study also aimed to investigate the effect of perceived organizational support on turnover intention. The regression analyses results showed that both quantitative and qualitative job insecurity perceptions of health workers positively affected their turnover intention. When health workers perceive risk of losing their job or job features, their intentions to leave the employer hospitals will increase. These findings confirmed previous research results (Davy et al., 1997; Hellgren et al., 1999; Staufenbiel \& König, 2010). In addition, the effect of quantitative job insecurity was weaker than the effect of qualitative job insecurity. These results were also consistent with the previous study of Hellgren et al. (1999). The reason of the weaker effect may be that the quantitative job insecurity could be associated to actual turnover behavior more than turnover intention depending on the changes in health labor market conditions mentioned above. It would be interesting for the future researches to test the relationships between dimensions of job insecurity and actual turnover behavior to determine the differences between the effects of quantitative and qualitative job insecurity on intention to leave and actual turnover behavior. The results also demonstrated that perceived organizational support had negative effect on turnover intention. This result was consistent with the results of previous studies (e.g. Galletta, Portoghese, Penna, Battistelli, \& Saiani, 2011; Newman et al., 2012). These results showed that when health workers perceive their hospitals' support positively and with high level $(M=3.41)$, their intention to leave their present hospital would be decreased. Thus, findings indicated the importance of perceived organizational support for health workers in evaluating and making a decision on maintaining working relations with their hospitals. Furthermore, the results put forward that perceived organizational support is also substantial for private hospital managements to strengthen the worker-organization bonds.

In the study, we also inspected possible mediator effect of perceived organizational support on the relationships between dimensions of job insecurity and turnover intention. In the first model, the results of the analysis did not meet the Baron-Kenny steps since there was not significant relationship between quantitative job insecurity and perceived organizational support. In addition, the mediation analysis results showed that indirect effect of quantitative job insecurity on turnover intention through perceived organizational support was not confident because low level of confidence interval of indirect effect was negative and upper level of confidence interval was positive. These findings were opposite to the previous study. We reached only one study (Zeytinoglu et al., 2011) used perceived organizational support as a mediator between job insecurity and turnover intention, but only quantitative dimension of the job insecurity was held by authors according to job insecurity items used in their study. The results of Zeytinoglu et al. (2011)'s study showed that perceived organizational support mediates the association between (quantitative) job insecurity and turnover intention among nurses in Canada, thus, this result is opposite to the findings of our study. The reason of the difference between findings of their study and the current study could be working conditions of employees and health care labor market conditions because researchers reported that $41 \%$ of participants of their study were part-time employees while all participants of the present study were full-time employees. In terms of our results, given that the health workers with high quantitative job insecurity were more prone to actual turnover than turnover intention as we mentioned above, perceived organizational support may lose its importance for these health workers with high quantitative job insecurity even though there was support of the hospital.

In the second model, conditions of Baron-Kenny steps were provided, and results of the mediation analysis implied that health workers' perceived organizational support partially mediates the effect of qualitative job insecurity on their turnover intention. When the health workers perceive strong hospital support, this perception indirectly absorbs the effect of insecurity perception about losing current job features on turnover intention. Therefore, especially in critical periods for hospitals and health workers, it is important to provide more intense formal or informal support to reduce health workers' intentions to quit the hospital. In addition, it should be considered that concerns about qualitative job insecurity decrease the perception of organizational support, and perceived organizational support has a strong effect on intention to leave. These findings also demonstrate the importance of level of perceived organizational support in terms of both health workers and private hospitals. Although there were studies using qualitative and quantitative dimensions of job insecurity as separate variables (e.g Laine et al., 2009), and using perceived organizational support as mediator (Zeytinoglu et al., 2011), we did not confront any study examined the mediator role of organizational support on separate relationships of these two dimensions of job insecurity with turnover intention. In this respect, we could say that our first model, which demonstrates the mediator role of perceived organizational support on the relationship between the qualitative dimension of job insecurity and intention to leave, was unique. Therefore, it is strongly suggested to researchers 
to examine effects of health workers' job insecurity perceptions related to job features on turnover intention in different samples.

When we combined especially results of second model with demographic characteristics of participants of the study, losing importance of perceived organizational support for health workers with high quantitative job insecurity was more meaningful. According to results, almost half $(47.9 \%)$ of the participants of the current study were 25 or less years old. As we noted above, the number of private hospitals grows faster than public hospitals, and this development enhances alternative job opportunities for health workers. There is another option for especially young health workers that in case of passing public personnel selection exam, they can have a job with better salary and other features in public hospitals. These demographic results and better job opportunities may attract particularly young health workers to actual turnover, and thus, perceived organizational support may become meaningless to them. In addition, inadequacy of nurses not only in Turkey but also all over the world is another factor that affects the intentions of health workers to leave the employer hospital. Since there is low health worker supply, health workers may find another job quite easily even though working conditions are similar among private hospitals in Turkey. Although working conditions are similar, this easiness of finding another job in another hospital increase the importance of hospital support for both health workers and private hospitals to make difference. In this subject, future researches are also needed to expand our knowledge in private health sector.

The study has several limitations and some suggestions for future researches that readers should consider. First, the generalization of the results of the study was limited since the sample of the study represents Balikesir, which is only one of 81 cities in Turkey. The results may have been different when the sample expanded to health workers from different private and, even, public hospitals in Turkey. There are also a great number of health workers working in public hospitals, but sample of the study did not represent them. Therefore, attaining a more varied and representative population would be progressive for future researches. In addition, cross-cultural studies would be helpful to understand the generalizability and differences between countries. Second, responses of the participants may be biased (e.g. social desirability bias) because of using self-report measures in the study. Although it was emphasized in the questionnaire that the answers will be used only for academic purpose, participants might be answered the questionnaire proper to possible expectations of the management. Therefore, using different methods to measure these variables is crucial to provide accurate results in future researches.

The results of the study suggest that the qualitative side of job insecurity is as important as quantitative side for health workers in emergence of an intention to leave their hospitals. The results also suggest that hospital support perception is an important factor in decreasing emergence of intention to leave the hospital. The results demonstrated the importance of hospital support perceptions because it has a mediator effect on the relationship between qualitative job insecurity and turnover intention. That is, the effect of qualitative job insecurity on turnover intention will diminish if health workers perceive high hospital support. Therefore, the results of our study suggest both developing work conditions of and giving formal and informal hospital support to health workers would increase individual and organizational performance, and provide constant quality of care and retaining qualified workforce. Additionally, not having a mediator effect of perceived organizational support between quantitative job insecurity and turnover intention in terms of healt workers in Turkey is an interesting finding for scholars. As noted above, the reason of such a finding could be that if health workers feel unsecure about totally losing their job, they may not care about support of their employer hospital anymore, and they might seek for another employer hospital. Thus, perceived organizational support would not mediate the effect of quantitative job insecurity on turnover intention. Therefore, it is important to inspect this mediating effect in different cultures and different sectors for the literature in future researches.

\section{References}

AlBattat, A. R. S., \& Som, A. P. M. (2013). Employee dissatisfaction and turnover crises in the Malaysian Hospitality industry. International Journal of Business and Management, 8(5), 62-71. http://dx.doi.org/10.5539/ijbm.v8n5p62

Ashford, S. J., Lee, C., \& Bobko, P. (1989). Content, causes and consequences of job insecurity: A theory-based measure and substantive test. Academy of Management Journal, 32(4), 803-829. http://dx.doi.org/10.2307/256569

Baron, R. M., \& Kenny, D. A. (1986). The Moderator-Mediator Variable Distinction in Social Psychological Research: Conceptual, Strategic, and Statistical Considerations. Journal of Personality and Social Psychology, 51(6), 1173-1182. http://dx.doi.org/10.1037/0022-3514.51.6.1173

Bora Başara, B., Güler, C., Yentür, G. K., Birge, B., Pulgat, E., \& Mamak Ekinci, B. (2012). Türkiye 
Cumhuriyeti Sağllk Bakanlı̆ğ Sağllk İstatistikleri Yıllı̆̆ 2012 [Turkish Republic Ministry of Health Annual Health Statistics 2012]. Sağlık Araştırmaları Genel Müdürlüğü, Türkiye Cumhuriyeti Sağlık Bakanlığı, Ankara, Turkiye. http://sbu.saglik.gov.tr/Ekutuphane/kitaplar/siy_2012.pdf

Cavanagh, S. J., \& Coffin, D. A. (1992). Staff turnover among hospital nurses. Journal of Advanced Nursing, 17(11), 1369-1376. http://dx.doi.org/10.1111/j.1365-2648.1992.tb01861.x

Cheng, G. H. L., \& Chan, D. K. S. (2008). Who suffers more from job insecurity? A meta analytic review. $\begin{array}{lllll}\text { Applied Psychology: An International } & \text { Review, }\end{array}$ http://dx.doi.org/10.1111/j.1464-0597.2007.00312.x

Daouk-Öyry, L., Anouze, A., Otaki, F., Dumit, N. Y., \& Osman, I. (2014). The JOINT model of nurse absenteeism and turnover: A systematic review. International Journal of Nursing Studies, 51(1), 93-110. http://dx.doi.org/10.1016/j.jpurstu.2013.06.018

Davy, J. A., Kinicki, A. J., \& Scheck, C. L. (1997). A test of job security's direct and mediated effects on withdrawal cognitions. Journal of Organizational Behavior, 18(4), 323-349. http://dx.doi.org/10.1002/(SICI)1099-1379(199707)18:4\%3C323::AID-JOB801\%3E3.3.CO;2-R

Ducharme, L. J., Knudsen, H. K., \& Roman, P. M. (2008). Emotional exhaustion and turnover intention in human service occupations: The protective role of coworker support. Sociological Spectrum: Mid-South Sociological Association, 28(1), 81-104. http://dx.doi.org/10.1080/02732170701675268

Eisenberger, R., Huntington, R., Hutchison, S., \& Sowa, D. (1986). Perceived organizational support. Journal of Applied Psychology, 71(3), 500-507. http://dx.doi.org/10.1037/0021-9010.71.3.500

Emberland, J. S., \& Rundmo, T. (2010). Implications of job insecurity perceptions and job insecurity responses for psychological well-being, turnover intentions and reported risk behavior. Safety Science, 48(4), 452-459. http://dx.doi.org/10.1016/j.ssci.2009.12.002

Galletta, M., Portoghese, I., Penna, M. P., Battistelli, A., \& Saiani, L. (2011). Turnover intention among Italian nurses: The moderating roles of supervisor support and organizational support. Nursing and Health Sciences, 13(2), 184-191. http://dx.doi.org/10.1111/j.1442-2018.2011.00596.x

Gaskin, C. J., \& Happell, B. (2014). On exploratory factor analysis: A review of recent evidence, an assessment of current practice, and recommendations for future use. International Journal of Nursing Studies, 51(3), 511-521. http://dx.doi.org/10.1016/j.jinurstu.2013.10.005

Greenhalgh, L., \& Rosenblatt, Z. (1984). Job insecurity: Toward conceptual clarity. Academy of Management Review, 9(3), 438-448. http://dx.doi.org/10.5465/AMR.1984.4279673

Hair, J., Black, W., Babin, B., \& Anderson, R. (2010). Multivariate data analysis: A Global Perspective (7th ed.). New Jersey, NY: Prentice-Hall.

Harris, R. B., Harris, K. J., \& Harvey, P. (2008). An examination of the impact of supervisor on the relationship between job strains and turnover intention for computer workers. Journal of Applied Social Psychology, 38(8), 2108-2131. http://dx.doi.org/10.1111/j.1559-1816.2008.00383.x

Hayes, A. F. (2013). Introduction to Mediation, Moderation, and Conditional Process Analysis: A Regression Based Approach. New York, NY: The Guilford Press.

Hayes, L. J., O’Brien-Pallas, L., Duffield, C., Shamian, J., Buchan, J., \& Hughes, F. (2006). Nurse turnover: A literature review. International Journal of Nursing Studies, 43(2), 237-263. http://dx.doi.org/10.1016/j.ijnurstu.2005.02.007

Hellgren, J., Sverke, M., \& Isaksson, K. (1999). A two dimensional approach to job insecurity: Consequences for employee attitudes and well-being. European Journal of Work and Organizational Psychology, 8(2), 179-195. http://dx.doi.org/10.1080/135943299398311

Hochwarter, W. A., Kacmar, C., Perrewé, P. L., \& Johnson, D. (2003). Perceived organizational support as a mediator of the relationship between politics perceptions and work outcomes. Journal of Vocational Behavior, 63(3), 438-456. http://dx.doi.org/10.1016/S0001-8791(02)00048-9

Kim, C. W., Lee, S. Y., Kang, J. H., Park, B. H., Park, S. C., \& Park, H. K. (2013). Application of revised Nursing Work Index to hospital nurses of South Korea. Asian Nursing Research, 7(3), 128-135. http://dx.doi.org/10.1016/j.anr.2013.07.003

Laine, M., Van der Heijden, B. I. J. M., Wickström, G., Haaselhorn, H. M., \& Tackenberg, P. (2009). Job 
insecurity and intent to leave the nursing profession in Europe. The International Journal of Human Resource Management, 20(2), 420-438. http://dx.doi.org/10.1080/09585190802673486

Mosadeghard, A. M. (2013). Occupational stress and turnover intention: Implications for nursing management. International Journal of Health Policy and Management, 1(2), 169-176. http://dx.doi.org/10.15171/ijhpm.2013.30

Newman, A., Thanacoody, R., \& Hui, W. (2012). The effects of perceived organizational support, perceived supervisor support and intra-organizational network resources on turnover intentions: A study of Chinese employees in multinational enterprises. Personnel Review, 41(1), 56-72. http://dx.doi.org/10.1108/00483481211189947

Ohana, M. (2012). Perceived organizational support as mediator of distributive justice and job satisfaction: The moderating role of group commitment. The Journal of Applied Business Research, 28(5), 1063-1072. http://www.cluteinstitute.com/ojs/index.php/JABR/article/view/7246/7316

Park, M., Lee, J. Y., \& Cho, S. (2012). Newly graduated nurses' job satisfaction: Comparison with allied hospital professionals, social workers, and elementary school teachers. Asian Nursing Research, 6(3), 85-90. http://dx.doi.org/10.1016/j.anr.2012.06.001

Perryer, C., Jordan, C., Firns, I., \& Travaglione, A. (2010). Predicting turnover intentions: The interactive effects of organizational commitment and perceived organizational support. Management Research Review, 33(9), 911-923. http://dx.doi.org/10.1108/01409171011070323

Podsakoff, N. P., LePine, J. A., \& LePine, M. A. (2007). Differential challenge stressor-hindrance stressor relationship with job attitudes, turnover intentions, turnover, and withdrawal behavior: A meta-analysis. Journal of Applied Psychology, 92(2), 438-454. http://dx.doi.org/10.1037/0021-9010.92.2.438

Ronen, S., \& Shenkar, O. (1985). Clustering Countries on Attitudinal Dimensions: A Review and Synthesis. The Academy of Management Review, 10(3), 435-454. http://dx.doi.org/10.2307/258126

Shields, M. A., \& Ward, M. (2001). Improving nurse retention in the National Health Service in England: The Impact of job satisfaction on intentions to quit. Journal of Health Economics, 20(5), 677-701. http://dx.doi.org/10.1016/S0167-6296(01)00092-3

Sora, B., Caballer, A., \& Peiró, J. M. (2010). The consequences of job insecurity for employees: The moderator role of job dependence. International Labour Review, 149(1), 59-72. http://dx.doi.org/10.1111/j.1564-913X.2010.00075.x

Staufenbiel, T., \& König, C. J. (2010). A model for the effects of job insecurity on performance, turnover intention, and absenteeism. Journal of Occupational and Organizational Psychology, 83(1), 101-117. http://dx.doi.org/10.1348/096317908X401912

Størseth, F. (2006). Changes at work and employee reactions: Organizational elements, job insecurity, and short-term stress as predictors for employee health and safety. Scandinavian Journal of Psychology, 47(6), 541-550. http://dx.doi.org/10.1111/j.1467-9450.2006.00548.x

Swerke, M., \& Hellgren, J. (2002). The nature of job insecurity: Understanding employment uncertainty on the brink of a new millennium. Applied Psychology: An International Review, 51(1), 23-42. http://dx.doi.org/10.1111/1464-0597.0077z

Sverke, M., Hellgren, J., \& Näswall, K. (2002). No security: A meta-analysis and review of job insecurity and its consequences. Journal of Occupational Health Psychology, 7(3), 242-264. http://dx.doi.org/10.1037/1076-8998.7.3.242

Takase, M. (2010). A concept analysis of turnover intention: Implications for nursing management. Collegian: The Australian Journal of Nursing Practice, Scholarship \& Research, 17(1), 3-12. http://dx.doi.org/10.1016/j.colegn.2009.05.001

Tett, R. P., \& Meyer, J. P. (1993). Job satisfaction, organizational commitment, turnover intention, and turnover: Path analysis based on meta-analytic findings. Personnel Psychology, 46(2), 259-253. http://dx.doi.org/10.1111/j.1744-6570.1993.tb00874.x

Wagner, C. M. (2010). Predicting nursing turnover with catastrophe theory. Journal of Advanced Nursing, 66(9), 2071-2084. http://dx.doi.org/10.1111/j.1365-2648.2010.05388.x

Youngblood, S. A., Mobley, W. H., \& Meglino, B. M. (1983). A Longitudinal Analysis of the Turnover Process. Journal of Applied Psychology, 68(3), 507-516. http://dx.doi.org/10.1037/0021-9010.68.3.507 
Zeytinoglu, I. U., Denton, M., \& Plenderleith, J. M. (2011). Flexible employment and nurses' intention to leave the profession: The role of support at work. Health Policy, 99(2), 149-157. http://dx.doi.org/10.1016/j.healthpol.2010.07.017

\section{Copyrights}

Copyright for this article is retained by the author(s), with first publication rights granted to the journal.

This is an open-access article distributed under the terms and conditions of the Creative Commons Attribution license (http://creativecommons.org/licenses/by/3.0/). 